$\underline{\text { Research Article }}$

\title{
STUDY OF ANTIMICROBIAL, ANALGESIC AND ANTICONVULSANT ACTIVITY OF NOVEL ISATIN DERIVATIVES
}

\author{
SRAVANTHI CHIRRA ${ }^{1 *}$, VENKATESHWAR RAO JUPALLY ${ }^{2}$
}

${ }^{1}$ Department of ???, Scient Institute of Pharmacy, Ibrahimpatnam, Rangareddy - 501 506, Telangana, India. ${ }^{2}$ Department of ???, Talla Padmavathi College of Pharmacy, Orus, Warangal - 506 002, Telangana, India. Email: sravanthichirra@gmail.com

Received: 15 March 2016, Revised and Accepted: 24 March 2016

Isatin is an endogenous compound and possess a wide variety of biological activities. In the present investigation, a different isatin derivatives such as novel isatin 3-[N-(4-substituted)-hydrazinyl-3-oxo prop 1-en-2yl) benzamides and their antimicrobial, analgesic and anticonvulsant activity was evaluated in different animal models. Antimicrobial activity by cup plate agar diffusion method. The analgesic activity was measured by Eddy's hot plate method, and reaction time was recorded when the animals licked their for and hind paws and jumped at before $0 \mathrm{hr}, 0.5 \mathrm{hr}, 1 \mathrm{hr}$ and $2 \mathrm{hrs}$ after administration of test drugs. 4-aminopyridine chemical induction method was employed for anticonvulsant activity. All the compounds were screened, among the screened compounds some compounds showed antimicrobial, analgesic and anticonvulsant activity with dose-dependent effect when compared with the control group.

Keywords: Isatin, Antibacterial, Antifungal, Analgesic, Anticonvulsant activity.

\section{INTRODUCTION}

The field of medicinal chemistry is devoted to the discovery and development of new molecules for treating many diseases. The process of establishing a new molecule is exceedingly complex and involves the talents of people from the field of heterocyclic chemistry. The biological and pharmacological properties shown by the many pharmaceutical industries and as a result of this, the synthesis of heterocyclic compounds emerged as powerful techniques for generating lead molecule.

Isatin derivatives have been an area of intensive research due to their applicability in the prevention and treatment of various disorders. The isatins are fundamental constituents of a number of natural and synthetic products with biological activity. The isatin is a versatile compound isolated in 1988 and reported to possess a wide range of biological activities. It is also a synthetically versatile substrate that can be used to prepare a large variety of heterocyclic compounds and acts as a raw material for synthesis of drugs. Schiff bases of isatin are known to possess a wide range of pharmacological properties that are anticonvulsant [1], antibacterial [2], antifungal [2], antiinflammatory [3], analgesic [3], antioxidant [4], and anticancer [5] activities. In view of the biological importance of these isatins, it was planned to synthesize a new series of isatin analogs and was evaluated for antimicrobial, analgesic, and anticonvulsant activity.

\section{METHODS}

\section{Chemicals}

All reagents were obtained from Sigma-Aldrich. All the solvents used in these studies were dried and distilled before use. Melting points were determined by open capillary tube method a dare uncorrected. The purity of the compounds checked by thin-layer chromatograph using glass plates coated with silica gel-G as an adsorbent, and spots were detected by iodine vapor.

\section{Biological activities}

\section{Antibacterial activity}

The compounds were tested in vitro for their antibacterial activity against two Gram-positive bacteria, viz., Bacillus subtilis and
Staphylococcus. Aureus and two Gram-negative bacteria, viz., Escherichia coli and Plasmodium vulgaris are pathogenic in human beings.

\section{Method}

Cup plate agar diffusion method using Muller-Hinton agar [6]

\section{Materials}

Nutrient agar, 18-24 hrs growth culture in nutrient agar, sterile Petri dishes, sterile micropipettes, sterile cotton swabs sterile cork borer $(8 \mathrm{~mm})$, and sterile test tubes.

Preparation of nutrient agar

Peptone $0.6 \mathrm{~g}$, yeast extract $0.15 \mathrm{~g}$, and dipotassium dihydrogen phosphate $0.13 \mathrm{~g}$ were dissolved in $100 \mathrm{ml}$ distilled water and $\mathrm{pH}$ was adjusted to 7.2 . This solution was sterilized by autoclaving at 15 p.s.i for 20 minutes.

Preparation of subculture

One day before these testings, inoculation of the above bacterial cultures were made in the nutrient agar and incubated at $37^{\circ} \mathrm{C}$ for $18-24 \mathrm{hrs}$.

Preparation of medium (Muller-Hinton Agar)

The $3.8 \mathrm{~g}$ of agar was dissolved into $100 \mathrm{ml}$ of distilled water, and the $\mathrm{pH}$ was adjusted to $7.4 \pm 0.2$. It was sterilized by autoclaving at 15 p.s.i for 20 minutes.

Preparation of test solutions

Each test compound $(5 \mathrm{~g})$ was dissolved in dimethylformamide $(5 \mathrm{ml})$ to give stock solution of concentration $1000 \mu \mathrm{g} / \mathrm{ml}$. Then, $0.1 \mathrm{ml}$ of this solution was used for testing.

Preparation of standard solution

Standard drug norfloxacin was used. The concentration was $100 \mu \mathrm{g} / \mathrm{ml}$.

Method of testing [7]

Muller - Hinton agar plates were prepared by pouring 10-15 $\mathrm{ml}$ of the medium into each sterilized Petri dish and were allowed to set at room temperature. The cell suspension was standardized to the density of $530 \mathrm{~nm}$ using spectrophotometer and was inoculated 
over the surface of agar medium using sterile cotton swab. The eight cups were scooped in each plate using a sterile cork borer of $8 \mathrm{~mm}$ diameter.

The solution of test compounds $(0.10 \mathrm{ml})$ were added in cups using micropipettes and these were incubated at $37^{\circ} \mathrm{C}$ for $48 \mathrm{hrs}$. The zone of inhibition was measured in mm of each organism.

\section{Antifungal activity}

Method

Cup-plate agar diffusion method using sabouraud-dextrose agar [8].

\section{Materials used}

Sabouraud-dextrose agar, 18-24 hrs growth culture on sabourauddextrose agar, sterile Petri dishes, sterile micropipettes, sterile cotton swabs sterile cork borer ( $8 \mathrm{~mm})$, and sterile test tubes.

\section{Preparation of sabouraud-dextrose agar}

Dextrose (40 g), neopeptone (10 g), and agar (15 g) were dissolved in distilled water $(1000 \mathrm{ml})$ and $\mathrm{pH}$ was adjusted to 5.5-6. This solution was sterilized by autoclaving at $120^{\circ} \mathrm{C}$ for 10 minutes.

\section{Preparation of sub-cultures}

One day before these testings, inoculation of the above fungal cultures were made in the sabouraud-dextrose agar and incubated at $37^{\circ} \mathrm{C}$ for 18-24 hrs. A suspension of cell from this culture was made in sterile distilled water. Five colonies more than $1 \mathrm{~mm}$ diameter were mixed with $5 \mathrm{ml}$ of normal saline and vortexed for 15 seconds. The cell density was adjusted using spectrophotometer at $530 \mathrm{~nm}$ with addition of normal saline.

\section{Preparation of test solutions}

Each test compound $(5 \mathrm{~g})$ was dissolved in dimethylformamide $(5 \mathrm{ml})$ to give stock solution of concentration $1000 \mu \mathrm{g} / \mathrm{ml}$, and then, $0.1 \mathrm{ml}$ of this solution was used for testing.

Preparation of standard solution

Standard drug norfloxacin was used. The concentration was $100 \mu \mathrm{g} / \mathrm{ml}$.

\section{Method of testing [8]}

Sabouraud-dextrose agar plates were prepared by pouring $10-15 \mathrm{ml}$ of the medium into each sterilized Petri dish and were allowed to set at room temperature. The cell suspension was standardized to the density of $530 \mathrm{~nm}$ using spectrophotometer and was inoculated over the surface of agar medium using sterile cotton swab. The eight cups were scooped in each plate using a sterile cork borer of $8 \mathrm{~mm}$ diameter, corresponding to control, standard and test solution.

Then, the solution of test compounds $(0.10 \mathrm{ml})$ were added in cups using micropipettes and these were incubated at $37^{\circ} \mathrm{C}$ for $48 \mathrm{hrs}$. The zone of inhibition was measured in millimeter of each organism.

\section{Analgesic activity [9]}

Materials

Polypropylene cages with paddy husk, Eddy's hot plate, pentazocine lactate as standard, test compounds, normal saline and double distilled water.

\section{Animals}

All the experiments were carried out using male, Swiss albino mice (25-30 g). On arrival, the animals were placed at random and allocated to treatment groups in polypropylene cages with paddy husk as bedding animals were housed at a temperature of $24 \pm 2^{\circ} \mathrm{C}$ and relative humidity of 30-70\%. A 12:12 light:day cycle was followed. All animals were allowed to free access to water with standard commercial chaw pallets. All the experimental procedures and protocols used in this study were reviewed by the Institutional Animals Ethics Committee with registration number is 1505/PO/a/11/CPCSEA.

\section{Drugs and chemicals}

The drugs and fine chemicals were purchased from Sigma-Aldrich, India. All other chemicals and solvents were obtained from local firms and were highest pure and analytical grade.

\section{Hot plate method [10]}

Each group of six mice selected for this study. One group selected as control and received the vehicle and one group received the standard drug pentazocine lactate $(30 \mathrm{mg} / \mathrm{kg}$ intraperitoneally [IP]), the drug concentration of $50 \mathrm{mg} / \mathrm{g}$ suspended in acacia was administered orally to other groups. The mice were placed on Eddy's hot plate kept at a temperature of $55 \pm 0.5^{\circ} \mathrm{C}$ for a maximum time of 15 seconds reaction time was recorded when the animals licked their fore and hind paws and jumped at before $0 \mathrm{hr}, 0.5 \mathrm{hr}, 1 \mathrm{hr}$ and $2 \mathrm{hrs}$ after administration of test drugs. In statistical analysis, all the results were expressed as mean \pm standard error. Data were analyzed using one-way ANOVA followed by Dunnett's test. $\mathrm{p}<0.05$ was considered as statistically significant. The results of analgesic activity of synthesized compounds are presented in Table 2 .

Table 1: Antibacterial activity of synthesized compounds

\begin{tabular}{llllll}
\hline \multirow{2}{*}{ S.No. } & Compounds & \multicolumn{4}{l}{ Zone of inhibition (in mm) } \\
\cline { 3 - 6 } & & B. subtilis & S. aureus & E. coli & P. vulgaris \\
\hline 1 & $\mathrm{~B}_{1}$ & 13 & 16 & 15 & 14 \\
2 & $\mathrm{~B}_{2}$ & 19 & 18 & 17 & 18 \\
3 & $\mathrm{~B}_{3}$ & 18 & 19 & 17 & 18 \\
4 & $\mathrm{~B}_{4}$ & 13 & 12 & 14 & 11 \\
5 & $\mathrm{~B}_{5}$ & 20 & 19 & 16 & 10 \\
6 & $\mathrm{~B}_{6}$ & 22 & 22 & 20 & 19 \\
7 & $\mathrm{~B}_{7}$ & 20 & 23 & 20 & 18 \\
8 & $\mathrm{~B}_{8}$ & 21 & 20 & 19 & 16 \\
9 & $\mathrm{~B}_{9}$ & 17 & 13 & 14 & 14 \\
10 & $\mathrm{~B}_{10}$ & 13 & 17 & 16 & 13 \\
11 & $\mathrm{~B}_{11}$ & 18 & 18 & 17 & 18 \\
12 & $\mathrm{~B}_{12}$ & 15 & 17 & 15 & 14 \\
13 & $\mathrm{~B}_{13}$ & 18 & 19 & 18 & 19 \\
14 & $\mathrm{~B}_{14}$ & 20 & 21 & 18 & 13 \\
Standard & Norfloxacin & 23 & 25 & 21 & 20 \\
\hline
\end{tabular}

B. subtilis: Bacillus subtilis, S. aureus: Staphylococcus aureus, E. coli: Escherichia coli, P. vulgaris: Proteus vulgaris

Table 2: Antifungal activity of synthesized compounds

\begin{tabular}{|c|c|c|c|c|c|}
\hline \multirow[t]{2}{*}{ S.No. } & \multirow[t]{2}{*}{ Compounds } & \multicolumn{4}{|c|}{ Zone of inhibition (in mm) } \\
\hline & & C. albicans & A. niger & C. verticulate & A. flavus \\
\hline 1 & $\mathrm{~B}_{1}$ & 15 & 16 & 15 & 13 \\
\hline 2 & $\mathrm{~B}_{2}$ & 18 & 22 & 20 & 14 \\
\hline 3 & $\mathrm{~B}_{3}^{2}$ & 17 & 16 & 18 & 13 \\
\hline 4 & $\mathrm{~B}_{4}^{3}$ & 18 & 19 & 16 & 12 \\
\hline 5 & $\mathrm{~B}_{5}^{4}$ & 15 & 18 & 13 & 10 \\
\hline 6 & $\mathrm{~B}_{6}^{5}$ & 21 & 22 & 20 & 17 \\
\hline 7 & $\mathrm{~B}_{7}^{\circ}$ & 24 & 25 & 22 & 18 \\
\hline 8 & $\mathrm{~B}_{8}$ & 22 & 26 & 20 & 19 \\
\hline 9 & $\mathrm{~B}_{9}^{\circ}$ & 14 & 17 & 19 & 12 \\
\hline 10 & $\mathrm{~B}_{10}$ & 13 & 15 & 17 & 11 \\
\hline 11 & $\mathrm{~B}_{11}^{10}$ & 17 & 20 & 18 & 15 \\
\hline 12 & $\mathrm{~B}_{12}^{11}$ & 14 & 16 & 18 & 16 \\
\hline 13 & $\mathrm{~B}_{13}^{12}$ & 23 & 22 & 19 & 17 \\
\hline 14 & $\mathrm{~B}_{14}$ & 15 & 13 & 16 & 10 \\
\hline Standard & Griseofulvin & 25 & 26 & 24 & 20 \\
\hline
\end{tabular}

C. albicans: Candida albicans, A. niger: Aspergillus niger, C. verticulate: ??? A. flavus: Aspergillus flavus 


\section{Anticonvulsant activity}

\section{Method}

Chemical induction by 4 -aminopyridine $[11,12]$ : The experimental animals divided into four groups each group containing six rats. One group served as normal control and received normal saline solution only, one group served as standard drug for induction of convulsions by injecting 4-aminopyridine $(13.3 \mathrm{mg} / \mathrm{kg}) \mathrm{IP}$, one group received standard drug phenytoin $(5 \mathrm{mg} / 150 \mathrm{~g}$ body weight $)$ IP, other groups received $4.5 \mathrm{mg}(30 \mathrm{mg} / \mathrm{kg}$ ) of test compounds suspended in tween-80 then administered IP as each compound per each group. All the groups except normal saline control were given 4-aminopyridine was measured and evaluated as a percent of the control. The control group received only the vehicle. When 4-aminopyridine was injected to standard convulsant group, the onset of action was noted (identified by jerky movement of whole body and tonic convulsions) and severity of convulsions due to the drug (4-aminopyridine).

The compounds 4-aminopyridine produces powerful tonic convulsions of body and limbs. The test compounds were injected to the respective groups and after $1 \mathrm{hr} 4$-aminopyridine was injected IP. The time taken for the onset of tonic convulsions was recorded for each group and results are represented in the Table 4.

\section{RESULTS AND DISCUSSION}

In this study, the compounds were synthesized as depicted in Scheme 1. 14 different novel isatin 3-[N-(4-substituted)-hydrazinyl-3-oxo prop 1-en-2yl) benzamides were prepared.

\section{Antibacterial activity}

Compounds $\mathrm{B}_{2}, \mathrm{~B}_{3}, \mathrm{~B}_{11}$, and $\mathrm{B}_{13}$ have shown promising antibacterial activity. However, $\mathrm{B}_{5}, \mathrm{~B}_{6}, \mathrm{~B}_{8}$, and $\mathrm{B}_{14}$ compounds have shown excellent activity.

\section{Antifungal activity}

Compounds $\mathrm{B}_{7}, \mathrm{~B}_{8}$, and $\mathrm{B}_{13}$ are have shown greater zone of inhibition as compared with griseofulvin. The compounds $\mathrm{B}_{2}, \mathrm{~B}_{6}$, and $\mathrm{B}_{12}$ have shown excellent activity.

\section{Analgesic activity}

The newly synthesized compounds were subjected for their analgesic activity by hot plate method. The compounds $\mathrm{B}_{7}, \mathrm{~B}_{8^{\prime}}, \mathrm{B}_{10}, \mathrm{~B}_{11}$, and $\mathrm{B}_{13}$ are showed good analgesic activity and remaining compounds showed very less to moderate activity when compared to standard drug pentazocine lactate.

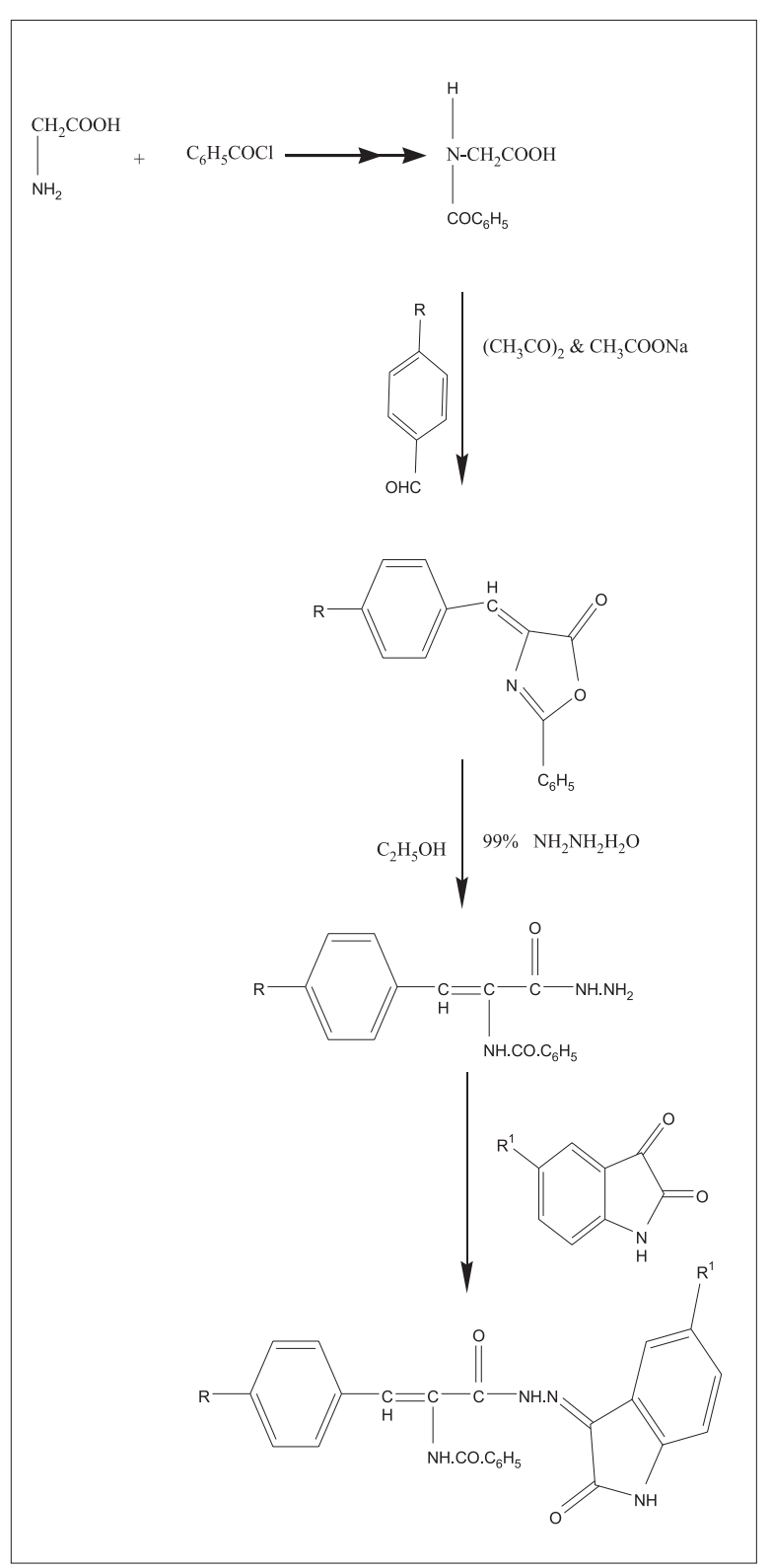

Scheme 1: ???

Table 3: Analgesic activity of synthesized compounds

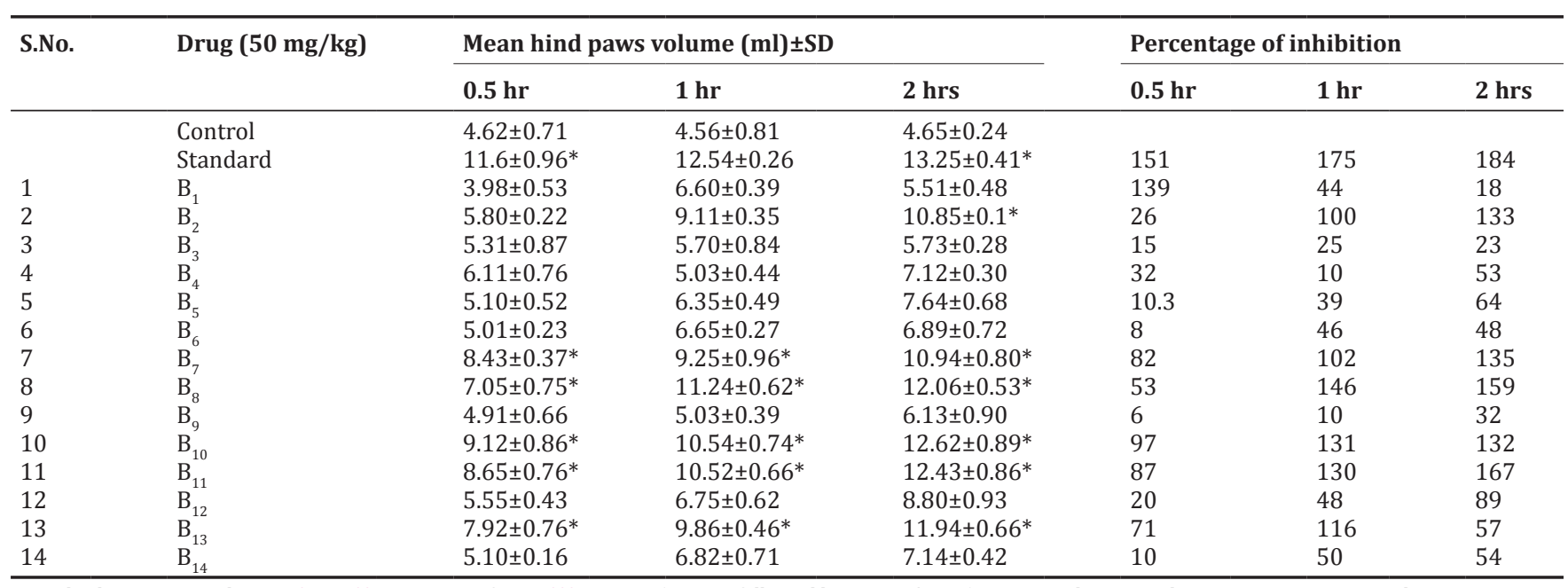

Standard-pentazocine lactate. ${ }^{*}:$ ?? , ${ }^{* *} \mathrm{p}<0.01$-significant, ${ }^{* * *} \mathrm{p}<0.001$ (ANOVA followed by Dunnet's test), Compared to control at respective time period 
Table 4: Anticonvulsant activity of synthesized compounds

\begin{tabular}{llll}
\hline S.No. & Compounds & Mean \pm SD & $\begin{array}{l}\text { Percentage } \\
\text { of inhibition }\end{array}$ \\
\cline { 1 - 2 } & 4-aminopyridine & $8.92 \pm 0.87$ & \\
& Standard & $23.34 \pm 0.48^{* * *}$ & 161.6 \\
1 & $\mathrm{~B}_{1}$ & $10.52 \pm 0.99$ & 17.9 \\
2 & $\mathrm{~B}_{2}$ & $11.05 \pm 0.29$ & 24 \\
3 & $\mathrm{~B}_{3}$ & $12.05 \pm 1.30$ & 35 \\
4 & $\mathrm{~B}_{4}$ & $15.73 \pm 1.49^{* *}$ & 76.3 \\
5 & $\mathrm{~B}_{5}$ & $11.35 \pm 1.55$ & 27.2 \\
6 & $\mathrm{~B}_{6}$ & $19.52 \pm 0.37^{* *}$ & 118.8 \\
7 & $\mathrm{~B}_{7}$ & $10.89 \pm 1.66$ & 22.0 \\
8 & $\mathrm{~B}_{8}$ & $19.23 \pm 0.84^{* * *}$ & 115.5 \\
9 & $\mathrm{~B}_{9}$ & $14.52 \pm 0.73^{* *}$ & 73.9 \\
10 & $\mathrm{~B}_{10}$ & $20.80 \pm 0.83^{* * *}$ & 133.1 \\
11 & $\mathrm{~B}_{11}$ & $17.62 \pm 1.40^{* * *}$ & 97.5 \\
12 & $\mathrm{~B}_{12}$ & $13.22 \pm 1.13$ & 48.2 \\
13 & $\mathrm{~B}_{13}$ & $21.31 \pm 1.50^{* * *}$ & 138.9 \\
14 & $\mathrm{~B}_{14}$ & $10.15 \pm 0.35$ & 13.7 \\
\hline
\end{tabular}

Standard-phenytoin, Statistically significant ${ }^{*} \mathrm{p}<0.05,{ }^{* *} \mathrm{p}<0.01,{ }^{* * *} \mathrm{p}<0.0001$ compared to control. SD: Standard deviation

\section{Anticonvulsant activity}

All the compounds have been evaluated for their anticonvulsant activity using 4-aminopyridine chemical induction method and phenytoin as standard drug. The compounds $\mathrm{B}_{8}, \mathrm{~B}_{10}, \mathrm{~B}_{11}$ and $\mathrm{B}_{13}$ have shown excellent potent activity compared to the standard drug.

\section{Antibacterial activity}

The compounds $\mathrm{B}_{2}, \mathrm{~B}_{3}, \mathrm{~B}_{11}$, and $\mathrm{B}_{13}$ have shown promising antibacterial activity. However, $\mathrm{B}_{5}, \mathrm{~B}_{6}, \mathrm{~B}_{8}$, and $\mathrm{B}_{14}$ compounds have shown excellent activity.

\section{Antifungal activity}

Compounds $\mathrm{B}_{7}, \mathrm{~B}_{8}$, and $\mathrm{B}_{13}$ have shown a greater zone of inhibition as compared with griseofulvin. The compounds $\mathrm{B}_{2}, \mathrm{~B}_{6}$, and $\mathrm{B}_{12}$ have shown excellent activity.

\section{Analgesic activity}

The newly synthesized compounds were subjected for their analgesic activity by hot plate method. The compounds $\mathrm{B}_{7}, \mathrm{~B}_{8}, \mathrm{~B}_{10}, \mathrm{~B}_{11}$, and $\mathrm{B}_{13}$ are showed good analgesic activity and remaining compounds showed very less to moderate activity when compared to standard drug pentazocine lactate.

\section{Anticonvulsant activity}

All the compounds have been evaluated for their anticonvulsant activity using 4-aminopyridine chemical induction method and phenytoin as standard drug. The compounds $\mathrm{B}_{8}, \mathrm{~B}_{10}, \mathrm{~B}_{11}$, and $\mathrm{B}_{13}$ have shown excellent potent activity compared to the standard drug.

\section{CONCLUSION}

Here, we concluded that novel isatin derivatives produce significant antimicrobial, analgesic, and anticonvulsant activities. It has been necessary from the results of preliminary investigations that there are a need further advanced studies, at least on a few of synthesized compounds.

\section{ACKNOWLEDGMENT}

The authors are thankful to Shri. K. Shaker Reddy, Chairman Scient Institute of Pharmacy, Ibrahimpatnam, Rangreddy and Talla Mallesham Secretary and Correspondent of LS Educational Society, Warangal to provide necessary facilities to carry out this work.

\section{REFERENCES}

1. Pandey SN, Sriram D, Nath G, DeClercq E. Synthesis, antibacterial, antifungal and anti HIV activities of Schiff and Mannich bases derived from isatin derivatives and $\mathrm{N}$-[4-(4'-chloro phenyl) thiazol-2yl) thiosemicarbazide. Eur J Pharm Sci 1999;9(1):25-31.

2. Ragavendran JV, Sriram D, Patel SK, Reddy IV, Bharathwajan N, Stables J, et al. Design and synthesis of anticonvulsants from a combined pthaimide-GABA-anilide and hydrazone pharmacophore. Eur J Med Chem 2007;42(2):146-51.

3. Pannerselvam P, Reddy RS, Murali K, Kumar NR. Synthesis, antiinflammatory and antimicribial activites of some novel Schiff's bases of 5-substituted isatin. Der Pharm Chem 2010;2(1):28-37.

4. Andreani A, Burnelli S, Granaiola M, Leoni A, Locatelli A, Morigi R, et al. New Isatin derivatives with antioxidant activity. Eur J Med Chem 2010;45(4):1374-8.

5. Gudipati R, Anreddy RN, Manda S. Synthesis, characterization and anticancer activity of certain 3-\{4-(5-mercapto-1,3,4-oxadiazole-2-yl) phenylimino \} indolin-2-one derivatives. Saudi Pharm J 2011;19(3):153-8.

6. Seely HW, Van Denmark PK. Microbes in Action, Laboratory Manual of Microbiology. $2^{\text {nd }}$ ed. San Francisco: W.H. Freeman \& Co.; 1975. p. 55.

7. Howard BJ. Clinical and Pathogenic Microbiology. $2^{\text {nd }}$ ed. Toranto: CV Mosby Company; 1987. p. 914.

8. Van Cutsem J, Kurata H, Matsuoka H, Mikami Y, Pfaller MA, Scalarone GM, et al. Antifungal drug susceptibility testing. J Med Vet Mycol 1994;32 Suppl 1:267-76.

9. Sondhi SM, Singhod N, Verma RP. Synthesis anti-inflammatory and analgesic activity evaluation of some 2-(9-acridinyl amino)pyridines and 2-(9-acridinyl amino/imino) thiazoles. Indian $\mathrm{J}$ Chem 1997;36B:620.

10. Vinegar R, Traldz JF, Selph JL. Concurrent evaluation and resolution in an acute inflammatory model of rat carrageenan induced pleurisy. Proc Soc Exp Bio Med 1973;143:711.

11. Chiutralekha, Dey PK. Pharacological screening of Valeriana wallichii Lallemantia royleana, Breynia rhamnoides and Evolvulus nummularius for sedative and anti-convulsant principles. Naturwissenchaften 1964;51:411.

12. Aakunuru J, Eedula K, Pasham V, Katls V, Reddy KS. Syntheisis of novel piperonal derivatives and evaluation of their anticonvulsant activity using a nano particular formulation. Int J Pharm Sci Nanotech 2009;2:435

Author Queries???

AQ1: Kindly provide department

AQ2: Kindly provide abstract structure as per journal style (Objective, Methods, Results, Conclusion)

AQ3: Kindly provide author initial

AQ4: Kindly cite Tables 1 and 3 in text part

AQ5: Kindly provide expansion

AQ6: Kindly cite significant value

AQ7: Kindly provide caption for Scheme 1

AQ8: Kindly provide significant value 